\title{
Synthesis, Characterization and Reactivity of Iron- and Cobalt-Pincer Complexes
}

\author{
Ashleigh D. Smith, Anu Saini, Laci M. Singer, Neha Phadke, and Michael Findlater* \\ ${ }^{\dagger}$ Department of Chemistry \& Biochemistry, Texas Tech University, Lubbock TX 79409, USA. \\ Supporting Information Placeholder
}

\begin{abstract}
The ${ }^{\mathrm{tBu}} \mathrm{PONOP}$ (2,6-bis(di-tert-butyl-phosphinito)pyridine) complexes of iron, $\left({ }^{\mathrm{tBu}} \mathrm{PONOP}\right) \mathrm{FeCl}_{2}(\mathbf{1})$ and $\left.\left({ }^{(\mathrm{Bu}} \mathrm{PONOP}\right) \mathrm{CoCl}_{2}(2)\right)$ have been prepared. Both complexes are paramagnetic and the solid-state structures of 1 and 2 were determined by single crystal X-ray diffraction studies. Analogous Fe and Co complexes of the ${ }^{\mathrm{tBu}} \mathrm{PNP}(2,6$-bis(ditert-butyl-phosphinomethyl)pyridine) ligand ( 3 and $\mathbf{4}$, respectively) were prepared to allow comparison between the closely related pincer ligands in the hydrosilylation of carbonyl moieties. All four complexes were found to be catalytically active when treated with $\mathrm{NaBEt}_{3} \mathrm{H}$, which was assumed to generate a metal-hydride species in-situ.
\end{abstract}

\section{INTRODUCTION}

Pincer ligands have emerged as a privileged class of ligand in organometallic chemistry and have seen widespread use in catalysis.[1-8] In particular, Ir-based pincers have been shown to be effective catalysts in a range of valuable catalytic transformations.[9-12] Among these pincer ligands, neutral tridentate systems such as PNP and PONOP have emerged as leading platforms for the study of catalytic reactions.[13-14] Given the high cost of precious metals such as Ir and Rh, the application of such ligands in base metal catalysis is no surprise and a number of reports have appeared in which such base-metal complexes were deployed in fields ranging from energy science to asymmetric catalysis.[15-16]

Given our interest in the hydrosilylation of carbonyl moieties using iron,[17] we turned our attention to the synthesis and reactivity of first-row metal PONOP and PNP pincer complexes. These types of PONOP and PNP ligands are readily available via salt metathesis reactions between 2,6-dihydroxypyridines or 2,6bis(bromomethyl)pyridines and dichlorophosphines to afford either PONOP or PNP pincer ligands, respectively. As befitting the status of a privileged class of ligands, the modular fashion in which they can be synthesized allows versatility in ligand platform design that is virtually unmatched. Given such versatility, it is surprising that only a few Fe- and Co-PONOP and PNP pincer complexes have been reported in the literature, although related systems have also been disclosed. An overview of cobalt and iron PNP and PONOP pincer systems, is depicted in Scheme 1.[18-26] It should be noted that several related iron and cobalt complexes containing anionic pincer-type PCP, POCOP, and $P N^{\text {pyrrole }} \mathrm{P}$ frameworks have been described.[27-33]

In this report, the synthesis, characterization, and reactivity of new (PONOP)M (M = Fe and Co) complexes are examined. Reactions of these metal PONOP complexes with $\mathrm{NaBEt}_{3} \mathrm{H}$ result in catalytically competent systems for the hydrosilylation of carbonyl groups. The synthesis and characterization of the, presumably, metal hydride complexes proved to be difficult because of the instability of these complexes, even at room temperature under inert atmosphere.

Scheme 1. Overview of Fe/Co PNP and PONOP Complexes Reported in the Literature
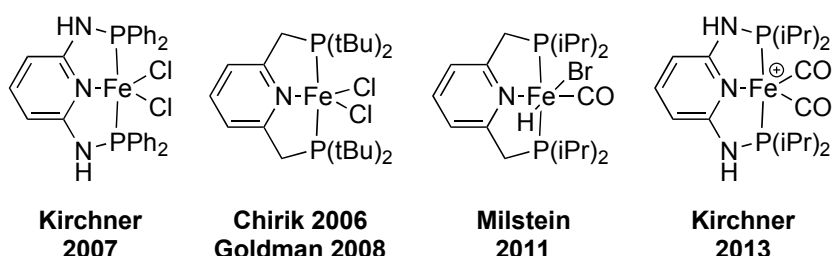

2007

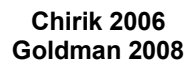
Milstein 2011
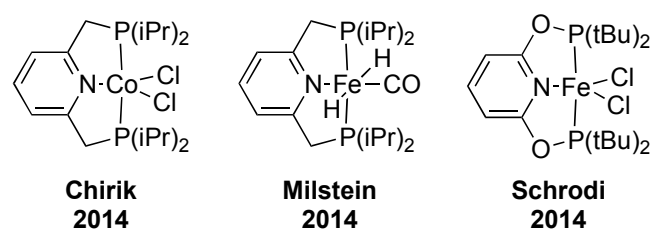

\section{RESULTS AND DISCUSSION}

Treatment of anhydrous $\mathrm{FeCl}_{2}$ or $\mathrm{CoCl}_{2}$ with the ligand tBuPONOP in THF affords the $16 e$ and $17 e$ complexes ( $\left.{ }^{\mathrm{t} u} \mathrm{PONOP}\right) \mathrm{FeCl}_{2}$ (1) and ( $\left.{ }^{\mathrm{t} u} \mathrm{PONOP}\right) \mathrm{CoCl}_{2}$ (2), respectively, in low yields after crystallization (Scheme 2). Both complexes exhibit broad NMR resonances consistent with paramagnetic compounds. Single crystals of both 1 and $\mathbf{2}$ were grown from concentrated toluene solutions at low temperature and analyzed by X-ray crystallography. The solid-state structures of $\mathbf{1}$ and $\mathbf{2}$ are shown in Figure 1.

Scheme 2. Synthesis of (PONOP)M and (PNP)M Complexes 
<smiles>CCCCCCCCCCCCCCCCCCCCCCCCC</smiles>
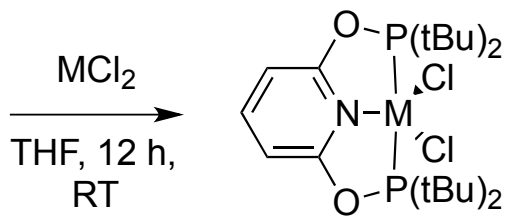

$$
\mathrm{M}=\mathrm{Fe} \text { (1); } \mathrm{Co} \text { (2) }
$$
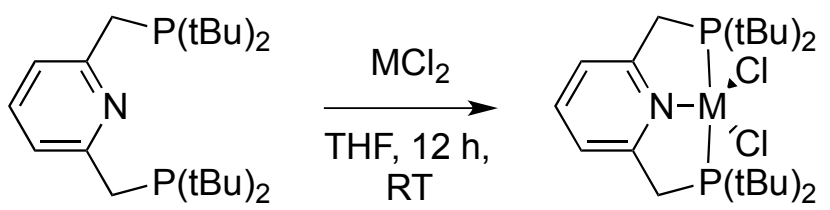

$$
\mathrm{M}=\mathrm{Fe} \text { (3); Co (4) }
$$

As we were preparing our manuscript, Schrodi and coworkers disclosed the solid-state structure of complex 1.[26] However, significant differences exist between the two structures. In our hands, 1 crystallized in the monoclinic space group rather than the previously reported triclinic system. Overall, the geometry is consistent with the previously reported crystal structure and with the analogous structure, $\left.{ }^{\mathrm{CBu}} \mathrm{PNP}\right) \mathrm{FeCl}_{2}$ (3).[34] However, the geometry around the iron center is best described as a distorted square pyramid with one chloride in the apical position and the nitrogen of the pyridine ring, the two phosphorus atoms and the remaining chlorine forming the basal plane. The structural distortion in complex 1 arises from an iron center, which is raised above the basal plane by a distance of $0.433 \AA$. The $\mathrm{Fe}-\mathrm{Cl}(1)$ and $\mathrm{Fe}-\mathrm{Cl}(2)$ distances are very different, 2.365(2) and 2.268(2) $\AA$, respectively. Similarly, N-Fe-Cl(1) and N-Fe$\mathrm{Cl}(2)$ bond angles are also dissimilar, 136.4(3) and $117.1(3)^{\circ}$, respectively. Close examination of the packing diagram reveals the cause to be the presence of secondary bonding interactions between the chloride ligands and adjacent ligand-based $\mathrm{H}$-atoms (Figure $\mathrm{1b}$ ). Curiously, a bifurcated non-bonding interaction is present involving both chlorides and a second interaction is observed only with $\mathrm{Cl}(1)$. This additional secondary bonding interaction accounts for the lengthening of the $\mathrm{Fe}-\mathrm{Cl}(1)$ bond distance.

The solid-state structure of 2 (Figure 1c) is essentially isostructural with that of $\mathbf{1}$, only less distorted. Like $\mathbf{1}$, analysis of the bonding in $\mathbf{2}$ unearths inequivalent cobaltchloride bond lengths for the apical and the equatorial sites (2.389(1) and 2.253(1) $\AA$, respectively). Once more, $\mathrm{N}-\mathrm{Co}-\mathrm{Cl}(1)$ and $\mathrm{N}-\mathrm{Co}-\mathrm{Cl}(2)$ bond angles also vary widely, $97.94(7)$ and $160.72(8)^{\circ}$, respectively. We attributed the distortions from ideal square pyramidal geometry in $\mathbf{1}$ to intermolecular non-bonding interactions. As anticipated, upon examination of the extended packing of $\mathbf{2}$ we observed a similar network of intermolecular interactions (Figure 1d). Thus, the presence of non-bonding interactions between the chloride ligands and adjacent ligandbased $\mathrm{H}$-atoms is revealed. However, unlike 1 there are no 'chelating' interactions between both chloride ligands and an adjacent $\mathrm{H}$-atom. We believe this is the reason the overall structure in $\mathbf{2}$ is less distorted that that of $\mathbf{1}$.

Hydrosilylation Studies. The reduction of the carbonyl, imine, or alkene functionality using a hydrosilylation strategy has emerged as a fundamental transformation in organometallic chemistry. ${ }^{1}$ Prevalent among the transition metal elements capable of such transformations are rare and expensive metals such as ruthenium, rhodium, and iridium.[35] In recent years, much effort has been devoted to the development of cheaper, first-row, transition metal based catalysts with cobalt and iron complexes proving a particular focus.[36] Guan et al synthesized phosphinite based pincer complexes of $\mathrm{Fe},[30,31,37]$ which were shown to be effective catalysts for reducing various aldehydes and ketones. Recently $\mathrm{Li}$ and coworkers disclosed imine based Fe hydrido complexes capable of catalyzing the reduction of the carbonyl moiety.[38] In contrast, hydrosilylation catalysts based upon Co have received only limited attention.[39]

Very recently Chirik and co-workers have reported on the catalytic hydrosilylation[40] and hydroboration[41] of carbon-oxygen and carbon-carbon multiple bonds employing PNP pincer cobalt complexes. However, to our knowledge no such studies have been conducted using the analogous PONOP systems. Thus, we decided to study the ability of complexes $\mathbf{1}$ and $\mathbf{2}$ to function as precatalysts in the hydrosilylation of aldehydes and ketones. In an effort to compare the relative effects of PONOPversus PNP-ligation to the metal center on catalytic performance we prepared the known (PNP) $\mathrm{MCl}_{2}$ (M $=\mathrm{Fe}$ and Co, 3 and $\mathbf{4}$ respectively) complexes using literature procedures.[20,34]

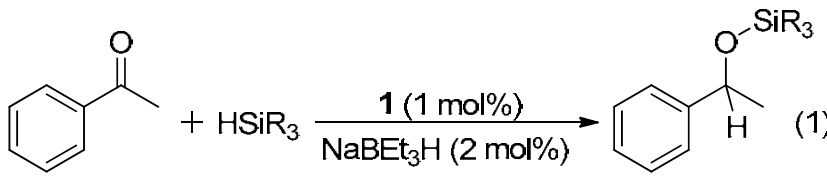

Optimization of reaction conditions. To probe for optimal reaction conditions we chose acetophenone as a model substrate. ${ }^{\text {tBu}} \mathrm{PNP}$ complex 1 was synthesized using literature protocols and used to rapidly screen for optimized hydrosilylation conditions. At first, no reaction was observed, however in situ activation of the dihalide with 2 equivalents of $\mathrm{NaBEt}_{3} \mathrm{H}$ (1M THF solution) afforded a catalytically competent system giving the reduced product as shown in eq 1 . The reaction is conveniently monitored by gas chromatography coupled with mass spectrometry (GC-MS). Both triethylsilane and triethoxysilane proved to be viable reducing agents for acetophenone (13 and $60 \%$, respectively, conversion to silylated product). Given the superior performance and lower cost of triethoxysilane we chose to pursue further studies with it in preference to triethylsilane. As shown in Table 1, we screened a variety of organic solvents but found that the highest conversions to silylated product could be obtained by running the reaction in neat triethoxysilane. 


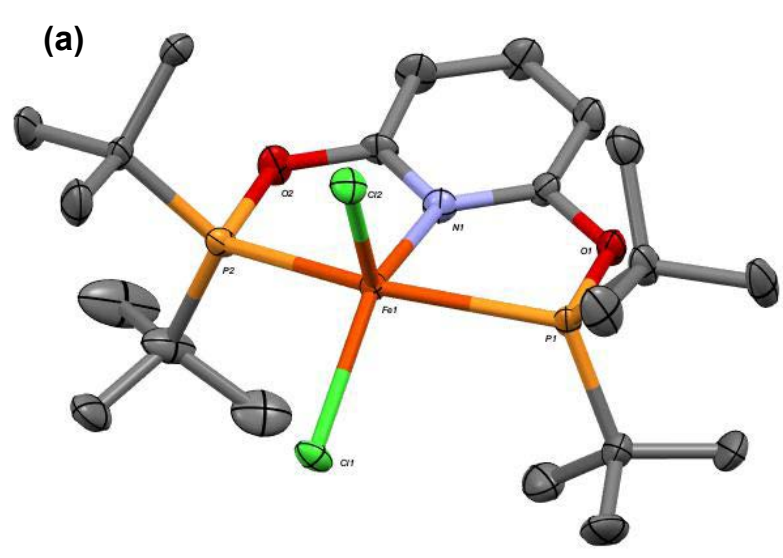

(b)

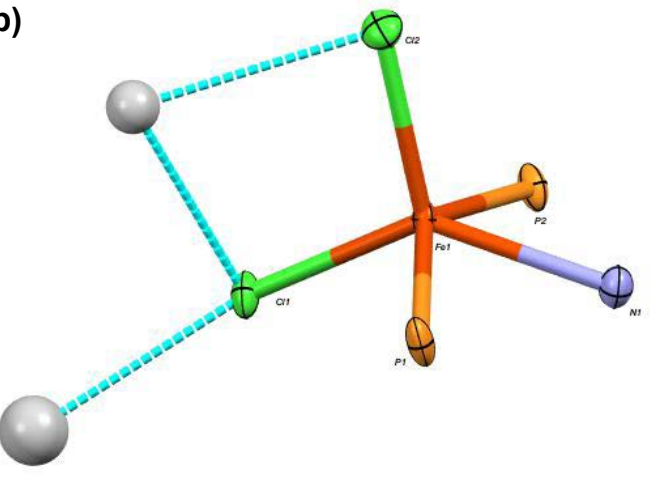

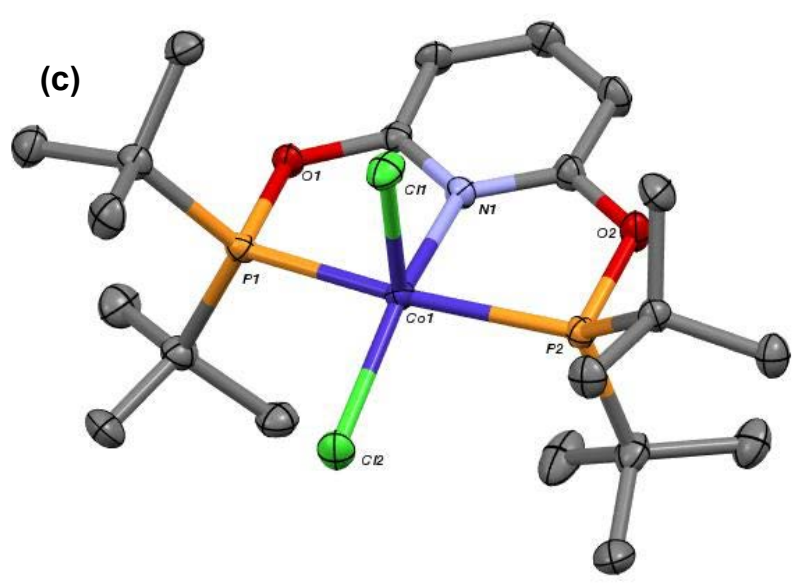

(d)

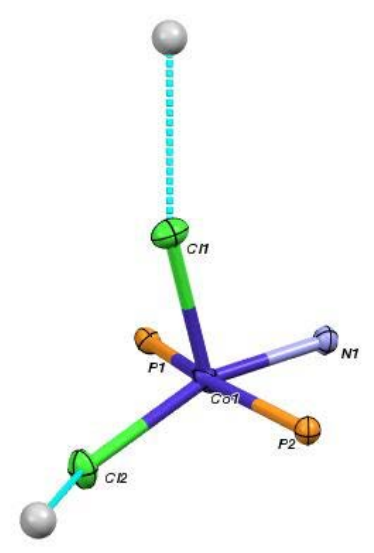

Figure 1. (a) Solid-state structure of 1. Hydrogen atoms omitted for clarity. Thermal ellipsoids at $30 \%$ probability. Key bond lengths $(\AA)$ and bond angles (deg): N1-Fe1 2.268(8), P1-Fe1 2.526(2), P2-Fe1 2.503(2), Fe1-Cl1 2.365(2), Fe-Cl2 2.268(2), P1-Fe1-P2 144.68(8), N1-Fe1-Cl1 136.4(3), N1-Fe1-Cl2 117.1(3), Cl1-Fe1-Cl2 106.53(7). (b) H-bonding contacts to chloride ligands account for distortion of trigonal-bipyramidal metal center geometry. (c) Solid-state structure of 2. Hydrogen atoms omitted for clarity. Thermal ellipsoids at $30 \%$ probability. Key bond lengths $(\AA)$ and bond angles (deg): N1-Co1 1.971(2), P1-Co1 2.281(1), P2-Co1 2.277(1), Co1-Cl1 2.389(1), Co1-Cl2 2.253(1), P1-Co1-P2 160.38(3), N1-Co1-Cl1 97.94(7), N1-Co1-Cl2 160.72(8), Cl1-Co1-Cl2 101.34(3). (d) H-bonding contacts to chloride ligands account for distortion of trigonal-bipyramidal metal center geometry.

Table 1. Solvent Effects in the Hydrosilylation of Acetophenone $^{\mathrm{a}}$

$\begin{array}{ccc}\text { Solvent } & \text { Temperature }\left({ }^{\circ} \mathrm{C}\right) & \text { Conversion }(\%)^{b} \\ \text { THF } & 66 & 60 \\ \text { Ether } & 35 & 58 \\ \text { Toluene } & 110 & 54 \\ \text { DCM } & 40 & 80 \\ \text { Neat } & 100 & 82\end{array}$

a. Reaction conditions: $\mathrm{FeCl}_{2}(1 \mathrm{~mol} \%)$, tBuPNP ( $1 \mathrm{~mol}$ $\%)$, Acetophenone $(0.154 \mathrm{~g}, 1.28 \mathrm{mmol})$, (EtO) 3 SiH $(0.213$ g, $1.29 \mathrm{mmol}), 1 \mathrm{M} \mathrm{NaBEt}{ }_{3} \mathrm{H}$ solution in THF (2 mol \%); b. Calculated using GC-MS analysis.
Initially, our catalytic experiments were conducted with isolated pre-catalysts 1-4. However, identical conversions are obtained using the operationally more convenient approach of generating the active catalyst in situ. Thus, reduced products can be accessed through simply mixing $\mathrm{FeCl}_{2}$ and ligand in a 1:1 ratio under the optimized reaction conditions. Importantly, no reaction products are observed if any component is withheld, i.e. the absence of ligand, metal dihalide or $\mathrm{NaBEt}_{3} \mathrm{H}$ results in isolation of unreacted starting materials. Based upon these results we screened the remaining pre-catalysts (2-4) for activity in the hydrosilylation of acetophenone employing our optimized reaction conditions and found all complexes were effective hydrosilylation precatalysts. Subsequently, we discovered that the formation of undesired by-products could be reduced by conducting the hydrosilylation reactions under slightly modified conditions; room temperature for 18-24h. After optimizing the reaction conditions, several aldehydes and ketones were reduced to demonstrate the generality 
of the catalytic hydrosilylation method under solvent-free conditions (Table 2).

Hydrosilylation of Ketones and Aldehydes. A broad range of ketone substitution patterns is tolerated under hydrosilylation conditions: long-chain aliphatics (2dodecanone), cyclic aliphatics (cyclohexanone), and aromatic substituents (acetophenone and dibenzoketone). Typically yields are satisfactory and range from $\sim 40-80 \%$, generally the sterically encumbered aliphatic ketones afforded the lowest yield. Similarly, aromatic aldehydes were cleanly reduced to siloxyalcohols by all catalyst variations ( $50-96 \%)$. Heterocyclic ketones and aldehydes (2-acetylthiophene and 2thiophenecarboxaldehyde, respectively) are also reduced, albeit in moderate yield. Some substrates, denoted below, were heated to $100^{\circ} \mathrm{C}$ for an additional 1824 hours to further maximize yields. Furthermore, to demonstrate the potential of our reaction protocol, we chose to hydrolyze a representative sample of our substrates to isolate the desired alcohol products. Thus, hydrolysis of the siloxy-intermediates using $2 \mathrm{M} \mathrm{NaOH}(2$ $\mathrm{mL})$ in $\mathrm{MeOH}(2 \mathrm{~mL})$ followed by evaporation of solvent afforded the corresponding alcohols. Purification via flash column chromatography was only required when starting material was remaining in the reaction mixture (isolated yields shown as parentheses in Table 2).

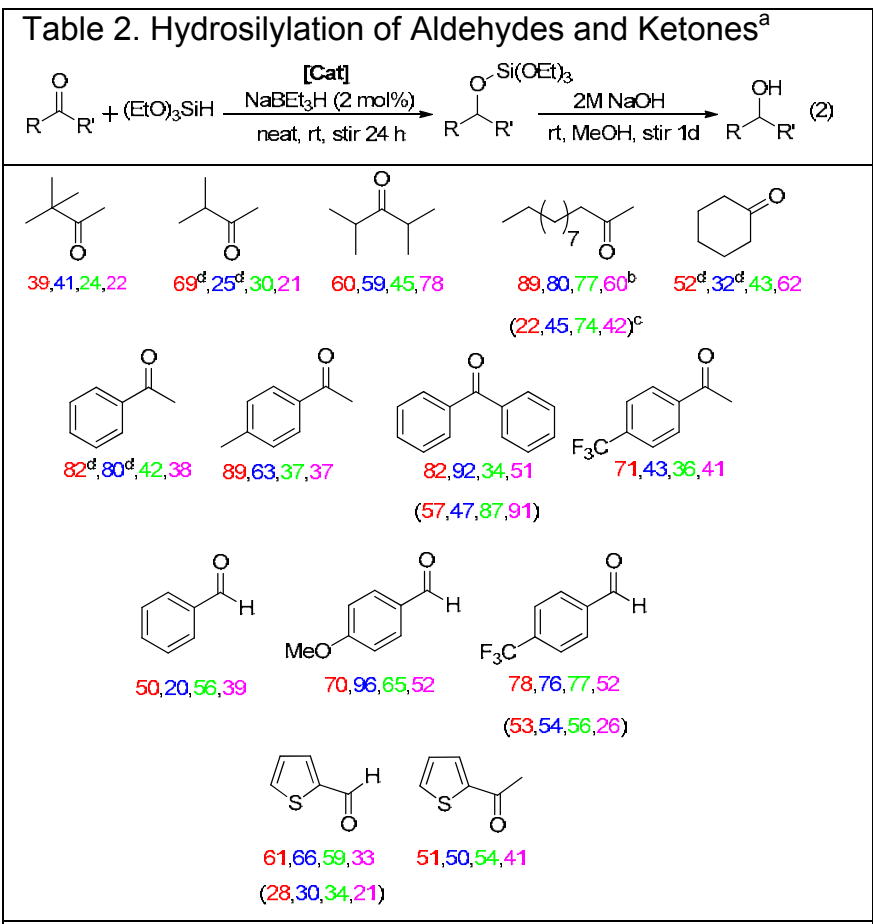

a. [Cat] $=$ Fe-tBuPNP, Co-tBuPNP, Fe-tBuPONOP, CotBuPONOP; b. Conversion numbers calculated using GCMS analysis; c. Isolated yields in the parentheses of the corresponding alcohols; d. After heating for $12 \mathrm{~h}$

Competition Experiment. To delineate the effects of electron withdrawing/donating substituents on the reactivity of aldehydes, competition reactions were performed using complex 1 and appropriately substituted benzaldehydes as shown in eqn 3 . In the competition experiment an equimolar mixture of all three substrates involved in hydrosilylation were mixed with a sub- stoichiometric amount (2.0 equiv.) of $(\mathrm{EtO})_{3} \mathrm{SiH}$. The progress of the reaction was monitored by GC-MS analysis, which revealed the silyl-ether products to be formed in a 1:2.5:4.5 ratio for the $-\mathrm{OMe}:-\mathrm{H}:-\mathrm{CF}_{3}$ substituted aldehydes. Thus, the relative rate of aldehyde hydrosilylation increases with electron-withdrawing groups in the para position, where the electron-deficient substrate is reduced most rapidly.

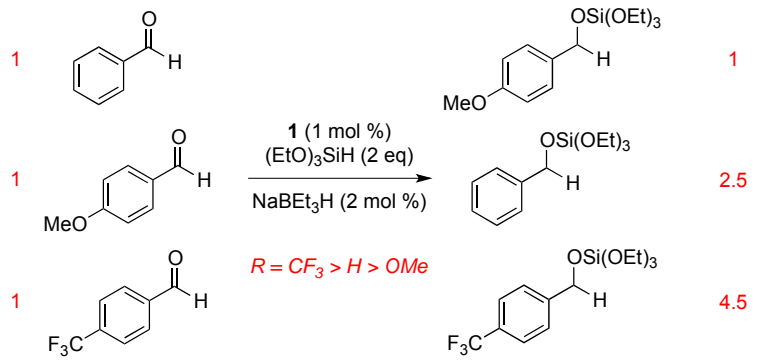

Proposed mechanism. The crucial role played by $\mathrm{Na}-$ $\mathrm{BEt}_{3} \mathrm{H}$ in activating the metal dihalide precatalysts $(\mathbf{1}-\mathbf{4})$ led us to propose the mechanism shown below (Scheme 3). Crucially, similar observations were reported by Huang's group in their related investigations of $\mathrm{Fe}-$ and Co-catalyzed alkene hydroboration.[42] Thus, salt metathesis of the halogens with the hydride reagent affords a metal(II) dihydride which may either retain (Scheme 3, red) or reductively eliminate (Scheme 3 , blue) dihydrogen to afford a catalyst based upon a $\mathrm{M}(\mathrm{II})$ or $\mathrm{M}(0) \mathrm{com}$ plex, respectively. Either metal is capable of precoordinating (activating) either the silane or carbonyl prior to hydrosilylation [37]. At this stage, the mechanism beyond activation of the dichloride remains a mystery to us and further examination of the mechanism is ongoing in our laboratory. In either case mechanistic scenario the binding of a carbonyl substrate in either an $\eta-1$ or $\eta-2$ manner is possible, although based upon recent theoretical calculations,[43] we favor the $\eta-1$ binding mode. Complicating this picture is the report of Kundu and Jones[44] in which they disclosed the reaction of [(PONOP)MCl] $[\mathrm{Cl}](\mathrm{M}=\mathrm{Ni}, \mathrm{Pd}, \mathrm{Pt})$ with $\mathrm{LiBEt}_{3} \mathrm{H}$ to afford a dearomatized ligand via hydride attack at the paraposition of the pincer, not the anticipated metal-hydride complex. Notably, these systems proved to remain active in the hydrosilylation of aldehydes and ketones. As of yet, we have no evidence of Jones-type ligand noninnocence in our complexes.

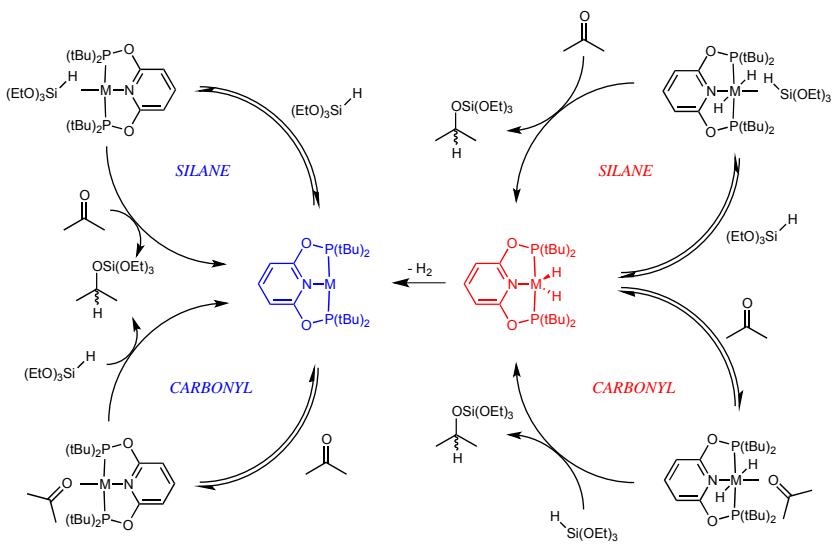


Scheme 1. Proposed Hydrosilylation Mechanism

\section{CONCLUSION}

In summary, we have developed an efficient catalyst system based on cheap, earth abundant and environment friendly transition metals ( $\mathrm{Fe}$ and $\mathrm{Co}$ ) for hydrosilylation of carbonyl compounds which is more appealing as compared to the currently used expensive methods. The active catalyst generated in situ conveniently reduces aldehydes and ketones. The details of the hydrosilylation mechanism are at present unknown and this remains an area of ongoing research in our group.

\section{APPENDIX A. SUPPLEMENTARY DATA}

CCDC-1431434 and CCDC-1431435 contain the supplementary crystallographic data for 1 and 2, respectively. These data can be obtained free of charge from the Cambridge Crystallographic Data Centre via http://www.ccdc.cam.ac.uk/data request/cif, or from the Cambridge Crystallographic Data Centre, 12 Union Road, Cambridge CB2 1EZ, UK; fax: (+44) 1223-336033; e-mail: deposit@ccdc.cam.ac.uk.

${ }^{1} \mathrm{H}$ NMR of the isolated primary and secondary alcohols and GC-MS data corresponding to conversion calculations. This material is available free of charge via the Internet at http://pubs.acs.org.

\section{AUTHOR INFORMATION}

\section{Corresponding Author}

*E-mail: michael.findlater@ttu.edu

\section{Notes}

The authors declare no competing financial interest.

\section{Appendix A.}

\section{ACKNOWLEDGMENT}

The authors acknowledge the Robert A. Welch Foundation (under Award No. D-1807), and Texas Tech University (Undergraduate Research Fellowship for A.D.S.) for financial support. The authors thank the National Science Foundation for funding the purchase of NMR instrumentation (Grant No. CHE-1048553) used in this project.

\section{EXPERIMENTAL SECTION}

General Synthetic Procedures. All reagents were purchased from commercial vendors, and were used without further purification unless otherwise noted. All syntheses were performed under inert atmosphere using standard glove-box or Schlenk techniques. Pincer ligand PNP is commercially available, PONOP was synthesized following the literature procedure.[14a] Complex 1, PONOP-FeCl 2 , was prepared according to the procedure reported by Schrodi and co-workers.[26] Complexes $\mathbf{3}$ and $\mathbf{4}$ were synthesized according to procedures published by Goldman [20] and Chirik.[19,23] Aldehyde and ketone substrates were obtained commercially, dried and degassed using the freeze-pump-thaw method before being stored in an argon-filled glovebox. Proton and carbon nuclear magnetic resonance spectra $\left({ }^{1} \mathrm{H}\right.$ NMR and ${ }^{13} \mathrm{C}$ NMR) were recorded on a Jeol $400 \mathrm{MHz}$ spectrometer with $\mathrm{Me}_{4} \mathrm{Si}$ or solvent resonance as the internal standard $\left({ }^{1} \mathrm{H} N M R, \mathrm{Me}_{4} \mathrm{Si}\right.$ at $0 \mathrm{ppm}$, $\mathrm{CHCl}_{3}$ at $7.24 \mathrm{ppm} ;{ }^{13} \mathrm{C} \mathrm{NMR}, \mathrm{Me}_{4} \mathrm{Si}$ at $0 \mathrm{ppm}, \mathrm{CDCl}_{3}$ at 77.0 ppm). ${ }^{1} \mathrm{H}$ NMR data are reported as follows: chemical shift, multiplicity $(\mathrm{s}=$ singlet, $\mathrm{d}=$ doublet, $\mathrm{t}=$ triplet, $\mathrm{q}=$ quartet, quint
$=$ quintet, sext $=$ sextet, sept $=$ septet, $\mathrm{br}=$ broad, $\mathrm{m}=$ multiplet), coupling constants $(\mathrm{Hz})$, and integration. Gas chromatography-mass spectrometry (GC-MS) was performed on an electron ionization time-of-flight (EI-TOF) mass spectrometer.

X-ray Crystallography. Data for PONOP- $-\mathrm{FeCl}_{2}$ and PONOP-CoCl ${ }_{2}$ complexes were obtained on a Bruker Smart Apex II CCD diffractometer. All data were collected at room temperature using graphite-monochromated Mo-K $\alpha$ radiation $(\lambda$ $=0.71073 \AA$ ). Intensity data were collected using $\omega$-steps accumulating area detector images spanning at least a hemisphere of reciprocal space. All the data were corrected for Lorentz polarization effects. A multi-scan absorption correction was applied using SADABS[45] or CrystalClear.[46] Structures were solved by direct methods and refined by full-matrix leastsquares against $F^{2}$ (SHELXTL[47]). All hydrogen atoms were assigned riding isotropic displacement parameters and constrained to idealized geometries.

Synthesis of Complex 2. 2,6-bis(ditertbutylphosphinito) pyridine $(50 \mathrm{mg}, 0.126 \mathrm{mmol}$ ) and cobalt (II) chloride (16 mg; $0.126 \mathrm{mmol}$ ) were dissolved in THF, producing a blue solution. The reaction was stirred for 18-24 hours at ambient temperature. This saturated THF solution was then layered with pentane and stored at $-30^{\circ} \mathrm{C}$, affording small, light blue crystals of 2 in low yield $(10 \mathrm{mg}, 0.02 \mathrm{mmol}, 15 \%) .{ }^{1} \mathrm{H}$ NMR $\left(\mathrm{CDCl}_{3}\right): \delta 0.03$ (br s, 2H, Py- $\left.\mathrm{H}_{m}\right), 1.13$ (s, 18H, C( $\left.\left(\mathrm{CH}_{3}\right)_{3}\right), 2.95$ (br s, $18 \mathrm{H}$, $\left.\mathrm{C}\left(\mathrm{CH}_{3}\right)_{3}\right)$, Py-Hp unobserved. Elem. Anal. Calcd for $\mathrm{C}_{21} \mathrm{H}_{39} \mathrm{Cl}_{2} \mathrm{CoNO}_{2} \mathrm{P}_{2}: \mathrm{C}, 47.65, \mathrm{H}, 7.43, \mathrm{~N}, 2.65$. Found $\mathrm{C}, 46.44$, $\mathrm{H}, 8.16, \mathrm{~N}, 2.83$.

Optimization Studies: Hydrosilylation of Acetophenone Using Complex 1. To an $20 \mathrm{~mL}$ glass vial, $\mathrm{FeCl}_{2}(1 \mathrm{~mol} \%)$ and tBuPNP (1 mol \%) were added and dissolved in the appropriate solvent (see Table 1). Subsequently, acetophenone $(0.15 \mathrm{ml}$, $1.28 \mathrm{mmol})$ and $(\mathrm{EtO})_{3} \mathrm{SiH}(1.29 \mathrm{mmol}, 1$ equiv) were then added, followed by $\mathrm{NaBEt}_{3} \mathrm{H}(2 \mathrm{~mol} \%)$ as a $1 \mathrm{M}$ solution in THF. The reaction was stirred for 24 hours at room temperature and the reaction progress was monitored using GC-MS.

General method for Hydrosilylation. To a known amount of mesitylene (GC standard) in a vial ${ }^{\mathrm{tBu}} \mathrm{PNP} /{ }^{\mathrm{BB}} \mathrm{PONOP}$ (1 $\mathrm{mol} \%), \mathrm{FeCl}_{2} / \mathrm{CoCl}_{2}(1 \mathrm{~mol} \%)$, substrate $(1.27 \mathrm{mmol})$, $(\mathrm{EtO})_{3} \mathrm{SiH}(1 \mathrm{eq})$ and $\mathrm{NaBEt}_{3} \mathrm{H}(2 \mathrm{~mol} \%)$ as a $1 \mathrm{M}$ solution in THF were added. After stirring this reaction mixture for 24 hours, GC-MS was taken and the mixture was hydrolytically quenched with $2 \mathrm{M} \mathrm{NaOH}(2 \mathrm{~mL})$ and $\mathrm{MeOH}(2 \mathrm{~mL})$. After stirring for $1 \mathrm{~d}$, the mixture was neutralized with $2 \mathrm{M} \mathrm{HCl}$. The product mixture was extracted with diethyl ether $(3 \times 5 \mathrm{~mL})$ and the organic layers were combined, washed with brine $(2 \times 5$ $\mathrm{mL}$ ), dried over $\mathrm{MgSO}_{4}$ and concentrated under reduced pressure to afford the corresponding alcohol as a crude product. Flash column chromatography with $5-20 \%$ (ethyl acetate : hexane) yielded analytically pure alcohol. ${ }^{1} \mathrm{H}$ NMR spectra of the isolated alcohols are provided as supplementary information.

\section{REFERENCES}

(1) (a) The Chemistry of Pincer Compounds; MoralesMorales, D., Jensen, C. M., Eds.; Elsevier: Amsterdam, 2007. (b) Morales-Morales, D. Mini-Reviews in Organic Chemistry 2008, 5, 141-152.

(2) Gunanathan, C.; Milstein, D. Acc. Chem. Res. 2011, 44 588.

(3) Haneline, M. R.; Heyduk, A. F. J. Am. Chem. Soc. 2006, $128,8410$.

(4) Chirik, P. J.; Weighardt, K. Science 2010, 327, 794.

(5) Mazzacano, T. J.; Mankad, N. P. J. Am. Chem. Soc. 2013, 135, 17258.

(6) Grutzmacher, H.-J. Angew. Chem., Int. Ed. 2008, 47, 1814.

(7) Vogt, M.; Gargir, M.; Iron, M. A.; Diskin-Posner, Y.; BenDavid, Y.; Milstein, D. Chem. Eur. J. 2012, 18, 9194. 
(8) Bichler, B.; Holzhacker, C.; Stoger, B.; Puchberger, M.; Veiros, L. F.; Kirchner, K. Organometallics 2013, 32, 4414.

(9) Choi, J.; MacArthur, A. H. R.; Brookhart, M.; Goldman, A. S. Chem. Rev 2011, 111, 1761-1779.

(10) Findlater, M.; Choi, J. W.; Goldman, A. S.; Brookhart, M. "Alkane Dehydrogenation" in Alkane C-H Activation by Single-Site Metal Catalysis, Perez, P. J., Ed.; Catalysis by Metal Complexes 2012, 38, Springer, New York, 2012.

(11) Ahuja, R.; Punji, B.; Findlater, M.; Supplee, C.; Schinski, W.; Brookhart, M.; Goldman, A. S. Nature Chemistry 2011, 3, 167-171.

(12) Lyons, T. W.; Guironnet, D.; Findlater, M.; Brookhart, M. J. Am. Chem. Soc 2012, 134, 15708-15711.

(13) (a) Kawatsura, M.; Hartwig, J. F. Organometallics 2001, 20, 1960. (b) Stambuli, J. P.; Stauffer, S. R.; Shaughnessy, K. H.; Hartwig, J. F. J. Am. Chem. Soc. 2001, 123, 2677. (c) Kloek, S. M.; Heinekey, D. M.; Goldberg, K. I. Organometallics 2006, 25, 3007. (d) van der Vlugt, J. I.; Pidko, E. A.; Vogt, D.; Lutz, M.; Spek, A. L.; Meetsma, A. Inorg. Chem. 2008, 47, 4442. (e) Tanaka, R.; Yamashita, M.; Nozaki, K. J. Am. Chem. Soc. 2009, 131, 14168. (f) van der Vlugt, J. I.; Siegler, M. A.; Janssen, M. I.; Vogt, D.; Spek, A. L. Organometallics 2009, 28, 7025. (g) Cucciolito, M. E.; D'Amora, A.; Vitagliano, A. Organometallics 2010, 29, 5878. (h) Gnanaprakasam, B.; Zhang, J.; Milstein, D. Angew. Chem., Int. Ed. 2010, 49, 1468. (i) Hahn, C. Organometallics 2010, 29, 1331. (j) Khaskin, E.; Iron, M. A.; Shimon, L. J. W.; Zhang, J.; Milstein, D. J. Am. Chem. Soc. 2010, 132, 8542. (k) Schwartsburd, L.; Iron, M. A.; Konstantinovski, L.; Diskin-Posner, Y.; Leitus, G.; Shimon, L. J. W.; Milstein, D. Organometallics 2010, 29, 3817. (I) Nakajima, Y.; Shiraishi, Y.; Tsuchimoto, T.; Ozawa, F. Chem. Commun. 2011, 47, 6332. (m) van der Vlugt, J. I.; Pidko, E. A.; Bauer, R. C.; Gloaguen, Y.; Rong, M. K.; Lutz, M. Chem.-Eur. J. 2011, 17, 3850. (n) van der Vlugt, J. I.; Pidko, E. A.; Vogt, D.; Lutz, M.; Spek, A. L. Inorg. Chem. 2009, 48, 7513.

(14) (a) Bernskoetter, W. H.; Hanson, S. K.; Buzak, S. K.; Davis, Z.; White, P. S.; Swartz, R.; Goldberg, K. I.; Brookhart, M. J. Am. Chem. Soc. 2009, 131, 8603. (b) Bernskoetter, W. H.; Schauer, C. K.; Goldberg, K. I.; Brookhart, M. Science 2009, 326, 553. (c) Salem, H.; Shimon, L. J. W.; Diskin-Posner, Y.; Leitus, G.; BenDavid, Y.; Milstein, D. Organometallics 2009, 28, 4791. (d) Findlater, M.; Bernskoetter, W. H.; Brookhart, M. J. Am. Chem. Soc. 2010, 132, 4534.

(15) Alberico, E.; Sponholz, P.; Cordes, C.; Nielsen, M.; Drexler, H.-J.; Baumann, W.; Junge, H.; Beller, M. Angew. Chem., Int. Ed. 2013, 52, 14162.

(16) Monfette, S.; Turner, Z. R.; Semproni, S. P.; Chirik, P. J. J. Am. Chem. Soc. 2012, 134, 4561.

(17) Phadke, N.; Findlater, M. Organometallics 2014, 33, 1618.

(18) Benito-Garagorri, D.; Wiedermann, J.; Pollak, M.; Mereiter, K.; Kirchner, K. Organometallics 2007, 26, 217-222.

(19) Trovitch, R. J.; Lobkovsky, E.; Chirik, P. J. Inorg. Chem 2006, 45, 7252-7260.

(20) Pelczar, E. M.; Emge, T. J.; Krogh-Jespersen, K.; Goldman, A. S. Organometallics 2008, 27, 5759-5767.

(21) Langer, R.; Leitus, G.; Ben-David, Y.; Milstein, D. Angew. Chem. Int. Ed 2011, 50, 2120-2124.

(22) Bichler, B.; Holzhacker, C.; Stöger, B.; Puchberger, M.; Veiros, L. F.; Kirchner, K. Organometallics 2013, 32, 4114-4121.

(23) Friedfeld, M. R.; Margulieux, G. W.; Schaefer, B. M.; Chirik, P. J. J. Am. Chem. Soc 2014, 136, 13178-13181.

(24) Semproni, S. P.; Hojilla Atienza, C. C.; Chirik, P. J. Chem. Sci. 2014, 5, 1956.
(25) Zell, T.; Ben-David, Y.; Milstein, D. Angew. Chem. Int. Ed 2014, n/a-n/a.

(26) DeRieux, W.-S. W.; Wong, A.; Schrodi, Y. Journal of Organometallic Chemistry 2014, 772-773, 60-67.

(27) Creaser, C. S.; Kaska, W. C. Inorganica Chimica Acta 1978, 30, L325-L326.

(28) Lian, Z.; Xu, G.; Li, X. Acta Cryst 2010, E66, 636.

(29) Hebden, T. J.; St John, A. J.; Gusev, D. G.; Kaminsky, W.; Goldberg, K. I.; Heinekey, D. M. Angew. Chem. Int. Ed 2010, 50, 1873-1876.

(30) Bhattacharya, P.; Krause, J. A.; Guan, H. Organometallics 2011, 30, 4720-4729.

(31) Bhattacharya, P.; Krause, J. A.; Guan, H. J. Am. Chem. Soc 2014, 136, 11153-11161.

(32) Kumar, S.; Mani, G.; Mondal, S.; Chattaraj, P. K. Inorg. Chem 2012, 51, 12527-12539.

(33) Kent, M. A.; Woodall, C. H.; Haddow, M. F.; McMullin, C. L.; Pringle, P. G.; Wass, D. F. Organometallics 2014, 33, 5686-5692.

(34) Zhang, J.; Gandelman, M.; Herrman, D.; Leitus, G.; Shimon, L. J. W.; Ben-David, Y.; Milstein, D. Inorg. Chim. Acta 2006, 359, 1955-1960.

(35) (a) Li, B.; Sortais, J. B.; Darcel, C. Chem. Commun. 2013, 49, 3691-3693. (b) Cheng, C.; Brookhart, M. Angew. Chem. 2012, 124, 9556-9558; Angew. Chem. Int. Ed. 2012, 51, 9422-9424. (c) Cheng, C.; Brookhart, M. J. Am. Chem. Soc. 2012, 134, 11304-11307.

(36) For recent reviews see: (a) Le Bailly, B. A. F.; Thomas, S. P. RSC Adv. 2011, 1, 1435-1445. (b) Zhang, M.; Zhang, A. Appl. Organometal. Chem. 2010, 24, 751757.

(37) Chakraborty, S.; Bhattacharya, P.; Dai, H.; Guan, H. Accounts of Chemical Research, 2015, 48, 1995-2003.

(38) Zuo, Z.; Sun, H.; Wang, L.; Li, X. Dalton Trans. 2014, $43,11716$.

(39) (a) Zhou, H.; Sun, H.; Zhang, S.; Li, X. Organometallics 2015, 34, 1479-1486. (b) Niu, Q.; Sun, H.; Li, X.; Klein, H.-F.; Flörke, U. Organometallics 2013, 32, 5235-5238. (c) Sauer, D. C.; Wadepohl, H.; Gade, L. H. Inorg. Chem. 2012, 51, 12948-12958. (d) Yu, F.; Zhang, X.-C.; Wu. F.-F.; Zhou, J.-N.; Fang, W.; Wu, J.; Chan, A. S. C. Org. Biomol. Chem. 2011, 9, 5652. (e) Brunner, H.; Amberger, K. J. Organomet. Chem. 1991, 417, C63-C65.

(40) Scheuermann, M. L.; Semproni, S. P.; Pappas, I.; Chirik, P. J. Inorg. Chem 2014, 53, 9463-9465.

(41) Obligacion, J. V.; Semproni, S. P.; Chirik, P. J. J. Am. Chem. Soc 2014, 136, 4133-4136..

(42) Zhang, L.; Zuo, Z.; Wan, X.; Huang, Z. Journal of the American Chemical Society. October 21, 2014, $p$ 141021131350000. (b) Cao, Y.; Zhang, Y.; Zhang, L.; Zhang, D.; Leng, X.; Huang, Z. Organic Chemistry Frontiers. September 23, 2014, pp 1101-1106. (c) Zhang, L.; Zuo, Z.; Leng, X.; Huang, Z. Angewandte Chemie International Edition. February 3, 2014, pp 2696-2700. (d) Peng, D.; Zhang, Y.; Du, X.; Zhang, L.; Leng, X.; Walter, M. D.; Huang, Z. Journal of the American Chemical Society. December 26, 2013, pp 19154-19166. (e) Zhang, L.; Peng, D.; Leng, X.; Huang, Z. Angewandte Chemie International Edition. February 18, 2013, pp 3676-3680.

(43) Wang, W.; Gu, P.; Wang, Y.; Wei, H. Organometallics 2014, 33, 847-857.

(44) Kundu, S.; Brennessel, W. W.; Jones, W. D. Inorganic Chemistry 2011, 50, 9443-9453.

(45) Sheldrick, G. M., SADABS v2008/1, 2008.

(46) CrystalClear-SM Expert v2.0. Rigaku Americas, The Woodlands, Texas, USA, and Rigaku Corporation, Tokyo, Japan, 2010.

(47) Sheldrick, G. M., Acta Crystallogr., 2008, A64, 112-122.. 


\section{Graphical Abstract}

Two PONOP-ligated $\mathrm{Fe}(\mathrm{II})$ and $\mathrm{Co}(\mathrm{II})$ complexes have been prepared and characterized.

Treatment of either complex with $\mathrm{NaBEt}_{3} \mathrm{H}$ affords catalytically competent earth abundant species capable of the hydrosilylation of aldehydes and ketones at room temperature.

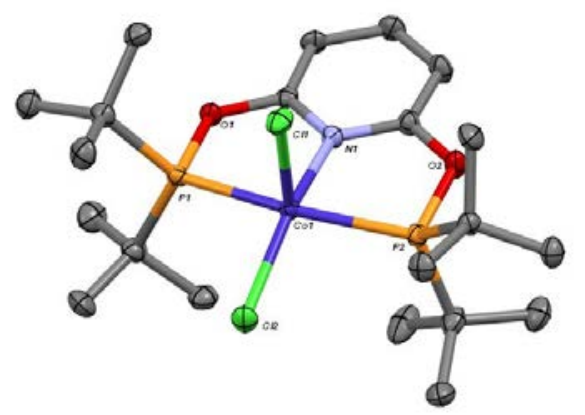

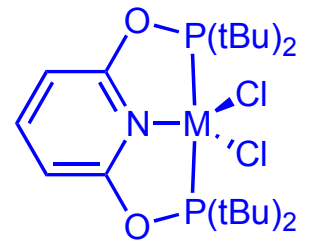

inactive

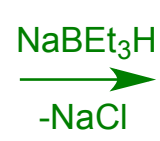

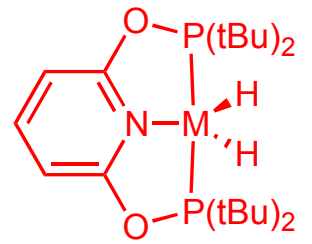

active 